\title{
Pemodelan Alat Pencegah Micro-Sleep Sebagai Upaya Mitigasi Kecelakaan Transportasi
}

\author{
Wibowo Harry Sugiharto ${ }^{1}$, Muhammad Imam Ghozali ${ }^{2}$, Alif Catur Murti ${ }^{3}$ \\ Program Studi Teknik Informatika, Fakultas Teknik, \\ Universitas Muria Kudus, Kudus - Indonesia ${ }^{123}$ \\ wibowo.harrys@umk.ac.id¹, imam.ghozali@umk.ac.id², alif.catur@umk.ac.id³
}

\begin{abstract}
Micro-sleep (MS) is a short sleep condition ranging from 1 to 30 seconds, where people who experience this condition fail to respond to motor sensors and become unconscious. Micro-sleep often occurs as a result of lack of sleep, but not always micro-sleep is caused by lack of sleep, some cases explain that micro-sleep sufferers are also experienced by those who do during monotonous work. Micro-sleep becomes very important when this condition involves dangerous conditions. Even though it's only a few seconds, of course this is very dangerous, and may be one of the main causes of accidents. By utilizing sensor technology, we can do realtime monitoring of the data of the owner, so that a tool that can detect the condition of the driver who has micro-sleep can be developed. With this information the micro-sleep detector will make a warning to the driver. This is expected to reduce the number of accidents caused by micro-sleep.
\end{abstract}

Keywords: Micro-sleep, Sensor, Warning System, Transportation Crash

\section{Abstrak}

Micro-sleep (MS) adalah kondisi tidur pendek berkisar antara 1 sampai 30 detik, dimana orang yang mengalami kondisi ini gagal merespon sensor motoric dan menjadi tidak sadarkan diri . Micro-sleep sering terjadi sebagai akibat dari kurang tidur, tapi tidak selamanya micro-sleep diakibatkan karena kurang tidur, beberapa kasus menjelaskan bahawa penderita micro-sleep juga dialami oleh mereka yang melakukan selama pekerjaan yang monoton .Micro-sleep menjadi hal yang sangat penting saat kondisi ini menyangkut kondisi yang membahayakan. Meski hanya beberapa detik, tentu ini sangat berbahaya, dan mungkin jadi salah satu penyebab utama kecelakaan. Dengan memanfaatkan teknologi sensor maka kita dapat melakukan pemantauan secara realtime dari data pengemuni, sehingga dapat dikembangkan sebuah alat yang mampu mendeteksi kondisi pengemudi yang mengalami micro-sleep. Dengan informasi ini alat pendeteksi micro-sleep akan melakukan peringatan kepada pengemudi. Hal ini diharapkan dapat menekan angka kecelakaan yang disebabkan oleh micro-sleep.

Kata kunci: Micro-sleep, Sensor, Sistem Peringatan, Kecelakaan Transportasi

\section{PENDAHULUAN}

Micro-sleep (MS) adalah kondisi tidur pendek berkisar antara 1 sampai 30 detik, dimana orang yang mengalami kondisi ini gagal merespon sensor motoric dan menjadi tidak sadarkan diri [1][2]. Micro-sleep sering terjadi sebagai akibat dari kurang tidur, tapi tidak selamanya micro-sleep diakibatkan karena kurang tidur, beberapa kasus menjelaskan bahawa penderita micro-sleep juga dialami oleh mereka yang melakukan selama pekerjaan yang monoton [3]. Micro-sleep menjadi hal yang sangat penting saat kondisi ini menyangkut kondisi yang membahayakan. Meski hanya 
beberapa detik, tentu ini sangat berbahaya, dan mungkin jadi salah satu penyebab utama kecelakaan [4]. Menurut U.K. road safety charity Brake, dari 1000 koresponden $45 \%$ pria dan $22 \%$ wanita yang disurvei mengaku melakukan microleeping saat mengemudi [5]. Lebih dari 1550 korban jiwa dan 40.000 cedera tidak fatal terjadi setiap tahun di Amerika Serikat diakibatkan oleh kondisi pengemudi mengantuk, kurang tidur [6]. Dalam sejarah banyak mencatat kecelakan yang diakibatkan oleh microsleep [7]. Diantaranya kecelakan yang disebabkan micro-sleep juga banyak terjadi di Indonesia, misalnya kecelakaan yang terjadi di jalan Tol Batang-Pemalang, Pekalongan pukul 11.00 WIB (25/6/2018) Penyebabnya karena pengemudi mengalami microsleep akkibatnya 4 orang korban mengalami kritis[8]. Data dari kepolisian republik Indonesia mencatat setidaknya terjadi 1018 kasus yang terjadi karena pengemudi mengantuk hanya dalam 15 Hari[8].

Beberapa ahli mendefinisikan microsleep memiliki ciri-ciri perilaku (anggukan kepala, kelopak mata terkulai, dll.)[3], Sementara yang lain bergantung pada pembacaan hasil EEG[2]. Karena ada banyak cara untuk mendeteksi Micro-sleep dalam berbagai konteks, ada sedikit kesepakatan tentang cara terbaik untuk mengidentifikasi dan mengklasifikasikan microsleep menggunakan detak jantung[9]. Dengan memanfaatkan teknologi sensor maka kita dapat melakukan pemantauan secara realtime dari data pengemuni, sehingga dapat dikembangkan sebuah alat yang mampu mendeteksi kondisi pengemudi yang mengalami micro-sleep. Dengan informasi ini alat pendeteksi micro-sleep akan melakukan peringatan kepada pengemudi. Hal ini diharapkan dapat menekan angka kecelakaan yang disebabkan oleh micro-sleep.

\section{METODOLOGI PENELITIAN}

Sebuah sistem analisis biosignal adaptif untuk mendeteksi peristiwaperistiwa micro-sleep disajikan. Sistem diterapkan pada elektroensefalogram dan elektrookulogram yang tercatat dari 23 relawan muda saat melakukan pemantauan dalam sebuah simulasi mengemudi secara monoton selama semalam. Dari sanalah lah dapat diklasifikasikan menjadi micro-sleep dan non microsleep. Metode yang digunakan adalah Delay Vector Variance. Perpaduan semua sinyal yang tercatat dan kedua jenis fitur menyebabkan error yang dihasilkan turun menjadi $11,2 \%$. Hal ini menunjukkan bahwa metodologi yang diusulkan mampu mendeteksi, tetapi tidak mampu untuk melakukan prediksi kejadian yang akan datang[10]. Selang dalam kinerja visuomotor sering dikaitkan dengan perilaku microsleep . Sistem peringatan yang mampu mendeteksi pola dalam EEG yang dapat diandalkan sebelum atau selama kejadian memiliki potensi untuk menyelamatkan banyak nyawa. pengembangan deteksi mocrosleep menggunakan Long Short'Term Memory (LSTM). Untuk melatih dan memvalidasi sistem, EEG, video wajah dan data pelacakan dikumpulkan dari 15 subjek yang melakukan tugas pelacakan visuomotor untuk 1 jam dalam 2 sesi. hal ini memberikan informasi tingkah laku pada peristiwa-peristiwa singkat dengan resolusi temporal yang baik. 
Sistem deteksi dirancang untuk bekerja secara real-time tanpa kalibrasi untuk masing-masing subjek. Hasil awal menunjukkan sistem tidak cukup andal untuk penggunaan umum, tetapi hasil dari beberapa sesi pelacakan mendorong penelitian lebih lanjut dari metode pendekatan yang dilaporkan [11].

Mengantuk didefinisikan oleh dua peristiwa hasil: penurunan kinerja (model Lane-Crossing) dan electroencephalogram (EEG) ditandai episode tidur (Microsleep Models). Untuk setiap hasil, kami menilai keakuratan set prediktor, termasuk atau tidak termasuk faktor driver, tindakan kelopak mata, dan pengukuran kinerja mengemudi. Kami juga membandingkan prediksi menggunakan interval waktu yang berbeda relatif terhadap peristiwa. Dengan memeriksa Area Di bawah receiver operating characteristic Curve (AUC), akurasi, sensitivitas, dan spesifisitas model prediktif, hasilnya menunjukkan bahwa dimasukkannya faktor driver individu meningkatkan AUC dan akurasi prediksi untuk kedua hasil. Hasil dari percobaan ini dapat bermanfaat bagi pengembangan deteksi ngantuk secara real-time dan membantu mengelola kantuk untuk menghindari kecelakaan [12].

Microsleep adalah tidur tidak disengaja yang berlangsung selama sepersekian detik atau hingga satu menit di mana seseorang gagal untuk menanggapi lingkungannya dan menjadi tidak sadar. Karena waktu yang sudah berlalu, microsleep dapat menciptakan situasi berbahaya, misalnya ketika seorang pengguna mengendarai mobil, setiap microsleep dapat mengakibatkan situasi yang tidak aman atau bahkan kematian. Dalam penelitian ini, dirancang sistem yang mendeteksi dan memprediksi microsleep menggunakan data yang dikumpulkan dari monitor denyut jantung yang mampu EKG. Hasil penelitian menunjukkan bahwa pendeteksian microsleep memiliki tingkat akurasi 96\% dapat memprediksi periode waktu di mana microsleep berikutnya akan dengan tingkat akurasi 83\%. Setelah microsleep terdeteksi atau diprediksi, sistem akan memperingatkan subjek[9].

Dalam penelitian telah digunakan beberapa tahapan prosedur penelitian yang dapat dijelaskan sebagai berikut: 
Jurnal Sains Komputer \& Informatika (J-SAKTI)

Volume 3 Nomor 1 Maret 2019, pp. 11-19 ISSN:2548-9771/EISSN:2549-7200

http://tunasbangsa.ac.id/ejurnal/index.php/jsakti

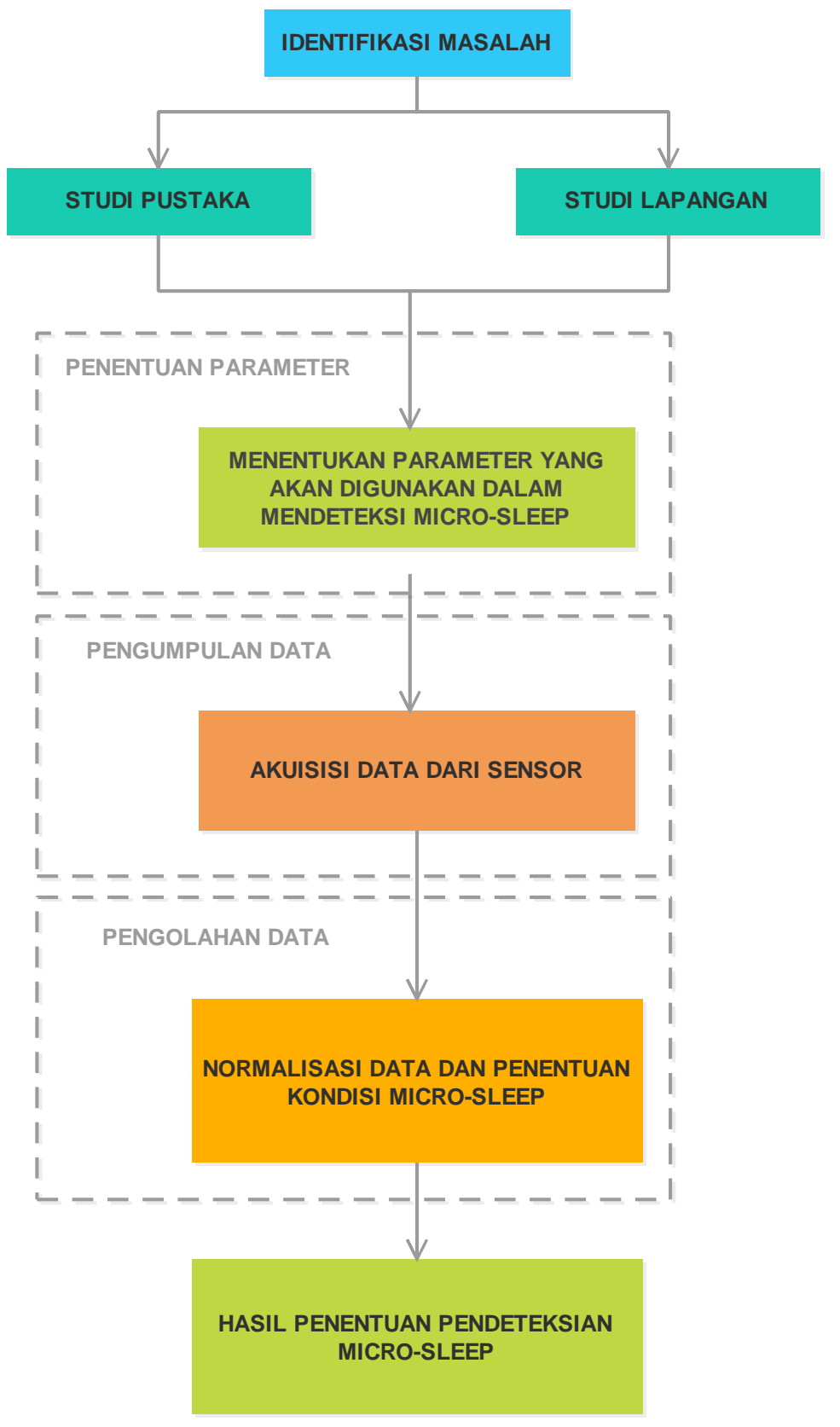

Gambar 1. Tahapan Penelitian

\subsection{Identifikasi Masalah}

Permasalahan yang ada dalam peneltian ini yakni banyak kecelakaan lintas terjadi terjadi karena adanya terjadi micro-sleep pada pengemudi.

\subsection{Penentuan Parameter}

Penentuan parameter / Screening Parameter dilakukan agar parameterparameter yang akan dipakai dalam penelitian tepat untuk menentukan status micro-sleep seseorang. 


\subsection{Pengumpulan Data}

Data didapat dari proses akuisisi data dari sensor yang digunakan. Sensor inilah yang akan mengeluarkan data mentah dari parameter yang dibutuhkan, untuk nantinya akan diolah untuk melakukan pendeteksian micro-sleep.

\subsubsection{Deteksi Detak Jantung}

Jantung adalah Jantung adalah organ vital di dalam tubuh manusia. Fungsinya untuk sirkulasi darah di dalam tubuh melalui vena. Frekuensi dan kekuatan Detak Jantung berbeda dari orang ke orang [13]. Sistem kardiovaskular dipengaruhi oleh jalur sympa-thetic dan parasimpatis dari sistem saraf otonom [14]. Analisis HRV mengkuantifikasi sistem saraf otonom dan dapat digunakan untuk itu dapat digunakan untuk membedakan antara respon stres dan respon istirahat [15].

\subsubsection{Sesor Detak Jantung}

Dalam melakukan deteksi jantung diperlukan sensor sebagai media peubah nilai fisis dari detak jantung manusia menjadi data yang nantinya kemudian diolah oleh sistem [16]. Beberapa sensor detak jantung yang mudah ditemukan adalah sebagai berikut:

a. KY-039

KY-039 merupakan sensor yang mendeteksi detak jantung menggunakan phototransistor. KY-039 menggunakan LED inframerah \& phototransitor untuk mendeteksi gelombang pada jari [17]. Cara kerja KY-039 adalah ketika LED menyala pada sisi atas jari, dan phototransistor berada ada sisi lainnya maka phototransistor digunakan untuk menangkap gelombang yang dipancarkan LED inframerah. Ketika ada aliran darah maka terdapat perbedaan cahaya yang ditangkap oleh phototransistor [18].

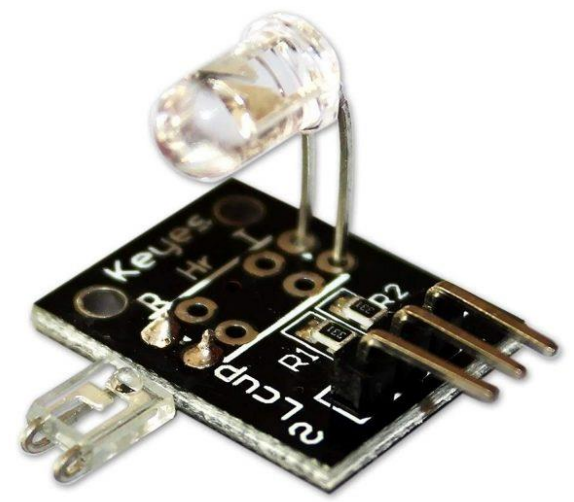

Gambar 2. Sensor KY-039

b. Pulse Sensor

Pulse sensor bekerja dengan cara memanfaatkan cahaya. Saat sensor ini diletakkan dipermukaan kulit, sebagian besar cahaya diserap atau dipantulkan oleh organ dan jaringan (kulit, tulang, otot, darah), namun 
sebagian cahaya akan melewati jaringan tubuh yang cukup tipis. Ketika jantung memompa darah melalui tubuh, dari setiap denyut yang terjadi, timbul gelombang pulsa (jenis seperti gelombang kejut) yang bergerak di sepanjang arteri dan menjalar ke jaringan kapiler di mana sensor pulsa terpasang. Pulse sensor dirancang untuk mengukur inter beat interval (IBI). IBI adalah selang waktu pada denyut jantung dalam mili detik dengan waktu momen sesaat dari jantung berdetak. BPM berasal setiap detak dari rata-rata setiap 10 kali IB [19]. Papan rangkaian pulse sensor ditempelkan pada jari tangan, kemudian node sensor akan membaca detak jantung, untuk selanjutnya mengirim hasil rekam detak jantung ke node koordinator yang terhubung dengan aplikasi monitoring [20].

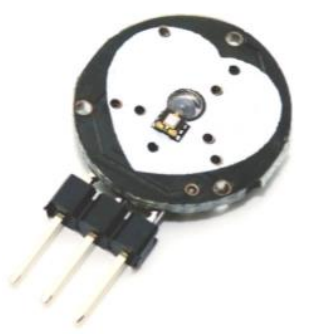

Gambar 3. Pulse Sensor

\subsection{Analisis Kebutuhan Sistem}

Mendefinisikan masalah, tujuan, kebutuhan, dalam pembangunan alat pendeteksi yang berhubungan dengan pendeteksian micro-sleep secara realtime. Adapun variabel yang diperlukan dalam sistem yang akan dibangun adalah untuk akuisisi data menggunakan embeded sensor yang telah dikalibrasi oleh perusahaan produsen sensor tersebut microcontroller, serta peripheral pendukung penelitian ini.

\subsection{Perancangan Sistem}

Tahapan ini memiliki tujuan untuk mentransformasikan kebutuhankebutuhan sistem yang dilakukan pada tahap analisis kebutuhan sistem kepada prototype alat yang akan dibangun nantinya. Tahapan perancangan sistem mendesain aliran kerja sistem dan merancang pemrograman yang diperlukan dalam pembangunan sistem informasi.Alur kerja sistem dimulai dengan menentukan masukan, penyimpanan, pemrosesan, dan keluaran.

\subsection{Implementasi Sistem}

Pada tahap ini akan dibuat alat pendeteksian microsleep sesuai dengan perancangan yang dibuat pada tahap perancangan sistem.

\section{HASIL DAN PEMBAHASAN}

Dalam melakukan deteksi microsleep maka data yang telah diakuisi oleh sensor kemudian akan di olah oleh system untuk mendapatkan kondisi mengantuk dari seseorang. 


\subsection{Normalisasi Data Hasil Deteksi Sensor}

Data Biometric diketahui merupakan data yang noise [21], Untuk melakukan normalisasi data perlu dilakukan penghapusan data detak jantung yang bernilai 0 atau RR Interval negatif. Kemudian Low Pass Filter melakukan normalisasi dengan menghapus data interval RR yang yang memiliki data lebih dari 20\% dari RR Interval sebelumnya.

\subsection{Feature Extraction}

pNN50 adalah angka dari sepasang urutan interval normal (NN) dengan nilah lebih besar dari $50 \mathrm{~ms}$ [22]. Kemudian akan dihitung perbedaan dengan interval normal dengan persamaan :

$$
N N_{k}-N N_{k-1}
$$

Kemudian kita menetapkan NN50 sebagai jumlah interval normal di mana kita memiliki perbedaan yang lebih besar dari $50 \mathrm{~ms}$. Kemudian melakukan perhitungan nilai pNN50 dengan persamaan :

$$
p N N 50=\frac{\text { NN50 }}{n} * 100
$$

\subsection{Pendeteksian Micro-sleep}

Pendeteksian micro-sleep adalah dengan melakukan evaluasi terhadap nilai pNN50 untuk respon jeda. Jika nilai menuntukkan diatas 20 maka subject telah mengantuk.

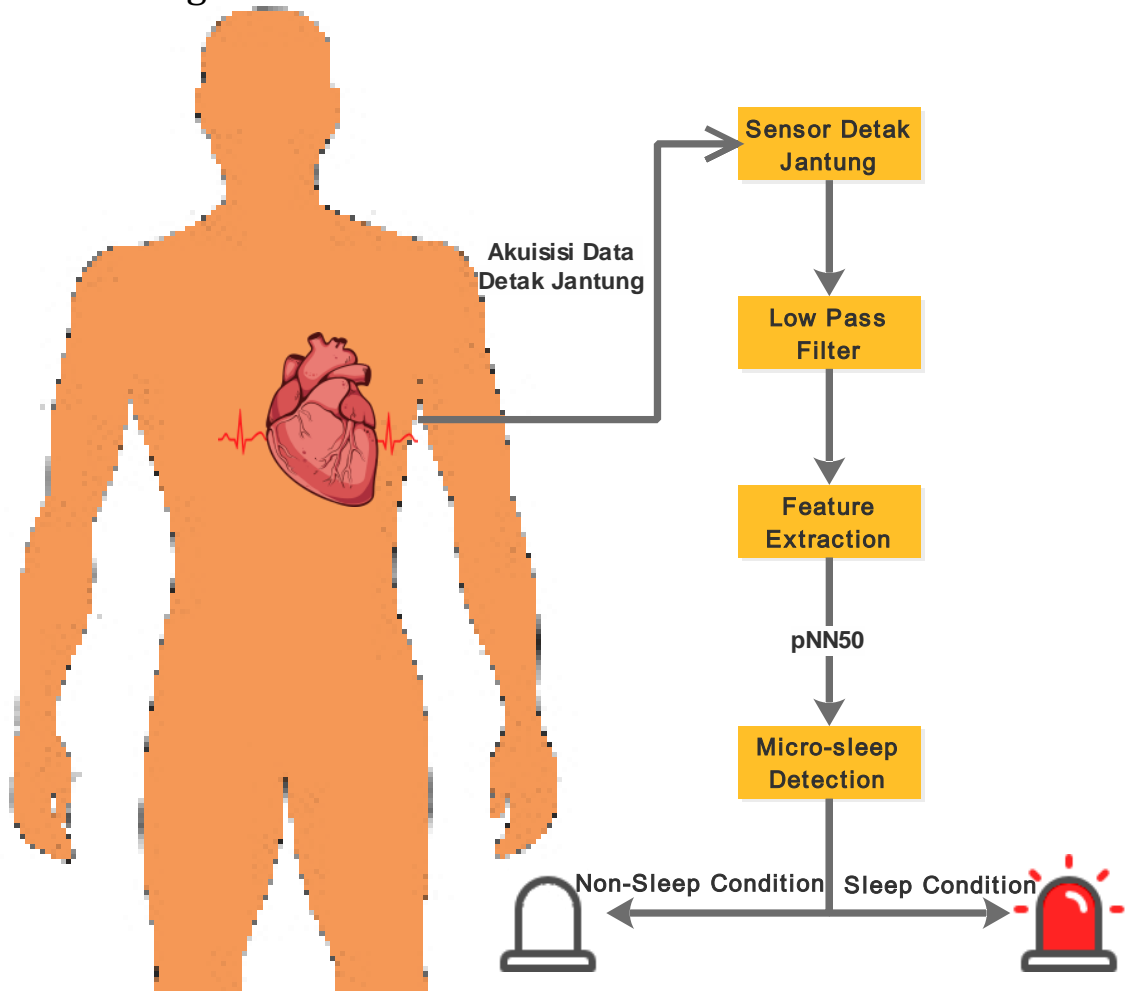

Gambar 4. Blok Diagram Deteksi Micro-sleep 


\section{SIMPULAN}

Dalam menentukan kondisi mengantuk pada seseorang bisa dilakukan dengan menggunakan detak jantung, Pada penelitian ini berhasil dibuat pemodelan dari sistem penentuan kondisi mengantuk menggunakan data hasil akuisisi dari sensor detak jantung. Data yang diterima akan melalui proses Low Pass Filter dan Feature Extraction sampai ahirnya bisa ditentukan kondisi menujuukan mengantuk jika respon nilai jeda diatas 20 .

\section{DAFTAR PUSTAKA}

[1] M. J. Thorpy et al., THE INTERNATIONAL CLASSIFICATION OF SLEEP DISORDERS, REVISED A merican A cademy of S leep M edicine. 2005.

[2] G. R. Poudel, C. R. H. Innes, P. J. Bones, R. Watts, and R. D. Jones, "Losing the struggle to stay awake: Divergent thalamic and cortical activity during microsleeps," Hum. Brain Mapp., 2014.

[3] Y. H. Chou, C. C. Chuang, J. K. Zao, L. W. Ko, and C. T. Lin, "An fMRI study of abrupt-awake episodes during behavioral microsleeps," in Proceedings of the Annual International Conference of the IEEE Engineering in Medicine and Biology Society, EMBS, 2011.

[4] R. Apinino, "Kenali Microsleep, Gangguan yang Bisa Bikin Kecelakaan." Liputan 6, 2017.

[5] D. Winterman, "Who, what, why: What is a micro-sleep?" BBC News, 2014.

[6] NCSDR/NHTSA Expert Panel on Driver Fatigue and Sleepiness, "Drowsy Driving and Automobile Crashes," Drowsy Driving, 2014. .

[7] A. J. Blaivas, R. Patel, D. Hom, K. Antigua, and H. Ashtyani, "Quantifying microsleep to help assess subjective sleepiness," Sleep Med., 2007.

[8] Y. O. Handono, "Waspada! Ketika 'Microsleep' Melanda, Nyawa Pengemudi Jadi Taruhanny," 2018.

[9] A. Watson and G. Zhou, "Microsleep Prediction Using an EKG Capable Heart Rate Monitor," in Proceedings - 2016 IEEE 1st International Conference on Connected Health: Applications, Systems and Engineering Technologies, CHASE 2016, 2016.

[10] M. Golz, D. Sommer, and D. Mandic, "Microsleep detection in electrophysiological signals," Proc. ICINCP 2005, no. May 2016, pp. 2-9, 2005.

[11] P. R. Davidson, R. D. Jones, and M. T. R. Peiris, "Detecting Behavioral Microsleeps using EEG and LSTM Recurrent Neural Networks," in 2005 IEEE Engineering in Medicine and Biology 27th Annual Conference, 2005.

[12] Y. Liang et al., "Prediction of drowsiness events in night shift workers during morning driving," Accident Analysis and Prevention, 2017.

[13] B. P. angin Ahmad Nawawi Harahap, "SISTEM PENGUKURAN DETAK JANTUNG MANUSIA MENGGUNAKAN MEDIA ONLINE DENGAN JARINGAN WI-FI BERBASIS PC," Saintia Fis. Univ. Sumatera Utara, pp. 1-7, 2013.

[14] J. Sztajzel, "Heart rate variability: A noninvasive electrocardiographic method to measure the autonomic nervous system," Swiss Medical Weekly. 2004.

[15] M. Altini, J. Penders, R. Vullers, and O. Amft, "Automatic heart rate normalization for accurate energy expenditure estimation. An analysis of activities of daily living and heart rate features.," Methods Inf. Med., 2014.

[16] S. Bennett, A History of Control Engineering, 1930-1955. Peter Peregrinus Ltd, 1993. 
Jurnal Sains Komputer \& Informatika (J-SAKTI)

Volume 3 Nomor 1 Maret 2019, pp. 11-19

ISSN:2548-9771/EISSN:2549-7200

http://tunasbangsa.ac.id/ejurnal/index.php/jsakti

[17] I. K. Resika Arthana, I. M. A. Pradnyana, and D. P. Y. Kurniati, "Sistem Monitoring Detak Jantung dan Lokasi Pasien," J. Pendidik. Teknol. dan Kejuru., vol. 15, no. 1, pp. 124-133, 2018.

[18] I. K. R. Arthana and I. M. A. Pradnyana, "Perancangan alat pendeteksi detak jantung dan notifikasi melalui sms," pp. 889-895, 2017.

[19] Fachrul Rozie, F. Hadary, and W. F. T. Pontia, "Rancang Bangun Alat Monitoring Jumlah Denyut Nadi / Jantung Berbasis Android," J. Tek. Elektro Univ. Tanjungpura, pp. 1-10, 2016.

[20] M. W. Sari and S. Wardani, "Rancang Bangun Aplikasi Monitoring Detak Jantung Melalui Finger Test Berbasis Arduino," J. EKSIS, vol. 9, pp. 105-112, 2016.

[21] T. Fritz and S. C. Muller, "Leveraging Biometric Data to Boost Software Developer Productivity," in 2016 IEEE 23rd International Conference on Software Analysis, Evolution, and Reengineering (SANER), 2016.

[22] T. L. Hartono, F. D. Setiaji, I. Setyawan, P. Studi, T. Elektro, and F. Teknik, "ALAT BANTU ANALISIS HEART RATE VARIABILITY," Techné J. Ilm. Elektrotek., vol. 12 No. 2 0, pp. 141-158, 2013. 